\title{
Global transcriptome profiling of wild soybean (Glycine soja) roots under $\mathrm{NaHCO}_{3}$ treatment
}

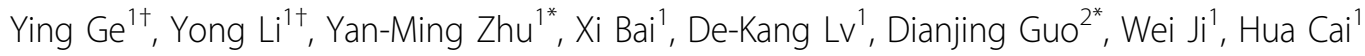

\begin{abstract}
Background: Plant roots are the primary site of perception and injury for saline-alkaline stress. The current knowledge of saline-alkaline stress transcriptome is mostly focused on saline $(\mathrm{NaCl})$ stress and only limited information on alkaline $\left(\mathrm{NaHCO}_{3}\right)$ stress is available.

Results: Using Affymetrix ${ }^{\circledR}$ Soybean GeneChip ${ }^{\oplus}$, we conducted transcriptional profiling on Glycine soja roots subjected to $50 \mathrm{mmol} / \mathrm{L} \mathrm{NaHCO}$ treatment. In a total of 7088 probe sets, 3307 were up-regulated and 5720 were down-regulated at various time points. The number of significantly stress regulated genes increased dramatically after $3 \mathrm{~h}$ stress treatment and peaked at $6 \mathrm{~h}$. GO enrichment test revealed that most of the differentially expressed genes were involved in signal transduction, energy, transcription, secondary metabolism, transporter, disease and defence response. We also detected 11 microRNAs regulated by $\mathrm{NaHCO}_{3}$ stress.

Conclusions: This is the first comprehensive wild soybean root transcriptome analysis under alkaline stress. These analyses have identified an inventory of genes with altered expression regulated by alkaline stress. The data extend the current understanding of wild soybean alkali stress response by providing a set of robustly selected,

differentially expressed genes for further investigation.
\end{abstract}

\section{Background}

Soil salinity-alkalinity is one of the major environmental challenges limiting crop productivity globally. For example, the western Songnen Plain of China, which has 3.73 million ha of sodic land, is one of the three major contiguous sodic soil regions in the world. Understanding the molecular basis of plant response under saline-alkaline conditions will facilitate biotechnology efforts to breed crop plants with enhanced tolerance to high saline-alkaline. Root is an important organ for carrying water and mineral nutrients to the rest of the plant. As the primary site of perception and injury for salinity and alkaline stress, roots provide an ideal target for study of the molecular mechanism underlying plant saline-alkaline stress tolerance and adaptation [1].

Soybean is rich in nutraceutical compounds, e.g., isoflavone and saponins. Its high symbiotic nitrogen fixing capacity $(100 \mathrm{Kg} / \mathrm{ha} /$ year; FAO data 1984$)$ helps to

\footnotetext{
* Correspondence: ymzhu2001@neau.edu.cn; djguo@cuhk.edu.hk

† Contributed equally

'Plant Bioengineering Laboratory, The College of Life Sciences, Northeast Agricultural University, Harbin, China

${ }^{2}$ State Key Lab for Agrobiotechnology and Department of Biology, The Chinese University of Hong Kong, Shatin, N.T., Hong Kong
}

replenish soil nitrogen. Therefore, soybean is an ideal crop for crop rotation and intercropping. Wild soybean exhibits much higher adaptability to suboptimal (i.e. stressful) natural environment compared to the cultivated soybean. The wild soybean (Glycine soja) line used in this study can germinate and set seed in the sodic soil at pH9.02 and survive in the nutrient solution with $50 \mathrm{mmol} / \mathrm{L} \mathrm{NaHCO}_{3}$. The physiological stress response of wild soybean has been described previously [2]. The obvious advantage of wild soybean over other extremophile model plants is that it can be directly compared with soybean cultivar to generate useful information for elucidation of plant stress tolerance and adaptation.

High throughput technologies, such as microarray, have been used to examine the gene expression patterns under various environmental cues in Arabidopsis [1,3-5], rice [6], wheat $[7,8]$, grape [9] and soybean [10]. Although studies on plant sodic stress has been conducted in perennial plant Leymus chinensis [11], Puccinellia tenuiora [12,13], Limonium bicolor [14] and Tamarix hispida [15] using cDNA array, the dynamic expression change under sodic stress is not yet available. Currently, commercialization microarrays are only 
available for a small number of species. Therefore, hybridization using a microarray for a closely related species was used and has demonstrated feasible, without discernible loss of information [16]. Ji has demonstrated that feasible to investigate the wild soybean's gene expression profile using the Affymetrix Soybean Genome Genechip based on the high similarity between the two allied species by comparison between the EST sequences of Glycine soja and Glycine max [17].

In the present study, we analyzed the transcriptome changes in Glycine soja roots under $\mathrm{NaHCO}_{3}$ treatments using Affymetrix ${ }^{\oplus}$ Soybean Genome Array. Our objectives were threefold: (1) to identify genes regulated by alkaline stress, (2) to identify genes co-regulated in a similar pattern and their dynamic change over the course of stress treatment, and (3) to identify the expression feature of gene family and their function category.

\section{Results and Discussion \\ Transcriptome profiling data}

The data discussed in this publication have been deposited in NCBI's Gene Expression Omnibus [18] and are accessible through GEO Series accession number GSE17883.

The assessment of duplicated microarray experiments using correlation analysis was shown in Additional file 1. The Pearson coefficients ranged from 0.953 to 0.993 . A total of 23849 probe sets were considered Present, among which 23741 showing consistent expression patterns in the replicates $(0<$ median $(\mathrm{SD} /$ mean $)<0.5)$ were used in the following analysis.

\section{Validation of microarray data by real-time quantitative PCR}

The real-time quantitative PCR (QRT-PCR) expressions of 16 candidate genes relative to a reference gene, gapdh, were compared with microarray expression in Figure 1. Although the magnitude of the transcript abundance varied between the microarray and QRTPCR, the patterns were similar. This indicates that the cross-species hybridization obtains real expression values of Glycine soja's genes.

\section{Identification of genes differentially expressed throughout the $\mathrm{NaHCO}_{3}$ stress}

A total of 7088 probe sets were differentially expressed in roots under saline-alkaline stress $(\mathrm{P}<0.05, \mathrm{q}<0.15)$ (Additional file 2) and their distribution at each time point was illustrated in Figure 2. Comparisons of the kinetics of changes in expression patterns revealed four features. First, 2851, 3127, 2881 and 2938 probe sets were significantly differentially expressed (up/downregulated) under $\mathrm{NaHCO}_{3}$ stress at 3, 6, 12 and $24 \mathrm{~h}$, respectively. The number of differentially expressed genes ranged from 3.37 to $9.01 \%$ of total genes. The number of significantly differentially expressed genes peaked at $6 \mathrm{~h}$ and decreased at 12 and $24 \mathrm{~h}$. This result is the same as the pattern found in Puccinellia tenuiflor [12] and Limonium bicolor [14] that the frequency of genes showing differential expression at $6 \mathrm{~h}$ is higher than that at 12, 24 and $48 \mathrm{~h}$. These suggest that the gene expressions change considerably after $6 \mathrm{~h}$ alkaline stress. In addition, it is noteworthy that the total number of differentially expressed genes and the dynamic patterns of up-regulated genes are similar to Arabidopsis transcriptome profile under salt stress but differed from that under cold, drought or osmotic stimuli [3]. This further suggests that plants have distinctive mechanisms in coping with ionic and physical stress. Second, genes up-regulated showed a trough at $6 \mathrm{~h}$ whilst, to a different extent, genes down-regulated showed a peak at $6 \mathrm{~h}$. This indicates a biphasic response of this organ to alkaline stress, and $6 \mathrm{~h}$ is the turning point. Third, almost no observable changes of transcripts were detected until after $3 \mathrm{~h}$ stress treatment. We found that it takes three hours for the roots to respond to sodic stress at transcription level. This might attribute to the timescale of molecular concentration and modifications (e.g. intake of $\mathrm{Na}^{+}$and $\mathrm{HCO}_{3}{ }^{-}$, transcription of mRNA). Cellular response to extracellular signals was reported to be a time-sequential process $[19,20]$. The process is most likely distributed over hours and requires the involvement of both protein signaling and gene regulation. Processes including changes of mRNA concentrations, protein complex formation, translocation in space, conformational changes or their molecular modifications, occur on different timescales ranging from milliseconds to seconds (e.g. induced conformational changes) via seconds and minutes (e.g. post-translational protein modification) up to hours and days for gene expression kinetics and/or even years by epigenetic regulation. Fourth, 3307 probe sets were up-regulated and 5720 were down-regulated. Moreover, the number of downregulated genes was greater than that of the up-regulated genes at each time point, which is contrary to the Arabidopsis profile under abiotic stresses [3]. We presume that this may attribute to the concomitant $\mathrm{Na}^{+}$, high $\mathrm{pH}, \mathrm{CO}_{3}{ }^{2-}$ and $\mathrm{HCO}_{3}{ }^{-}$in the $\mathrm{NaHCO}_{3}$ solution. Under multiple stress condition, plants suffer more severe injury than that of a single stress.

The Venn diagram (Figure 3) showed that the number of specifically up-regulated genes ranged from 50.71 to $78.10 \%$ of total genes at each time point. Only two probe sets were constantly up-regulated and 31 were constantly down-regulated at $3 \mathrm{~h}, 6 \mathrm{~h}, 12 \mathrm{~h}$ and $24 \mathrm{~h}$. One of the two up-regulated probe sets (Gma.56.1.S1 at) encodes a putative phosphoenolpyruvate carboxylase 


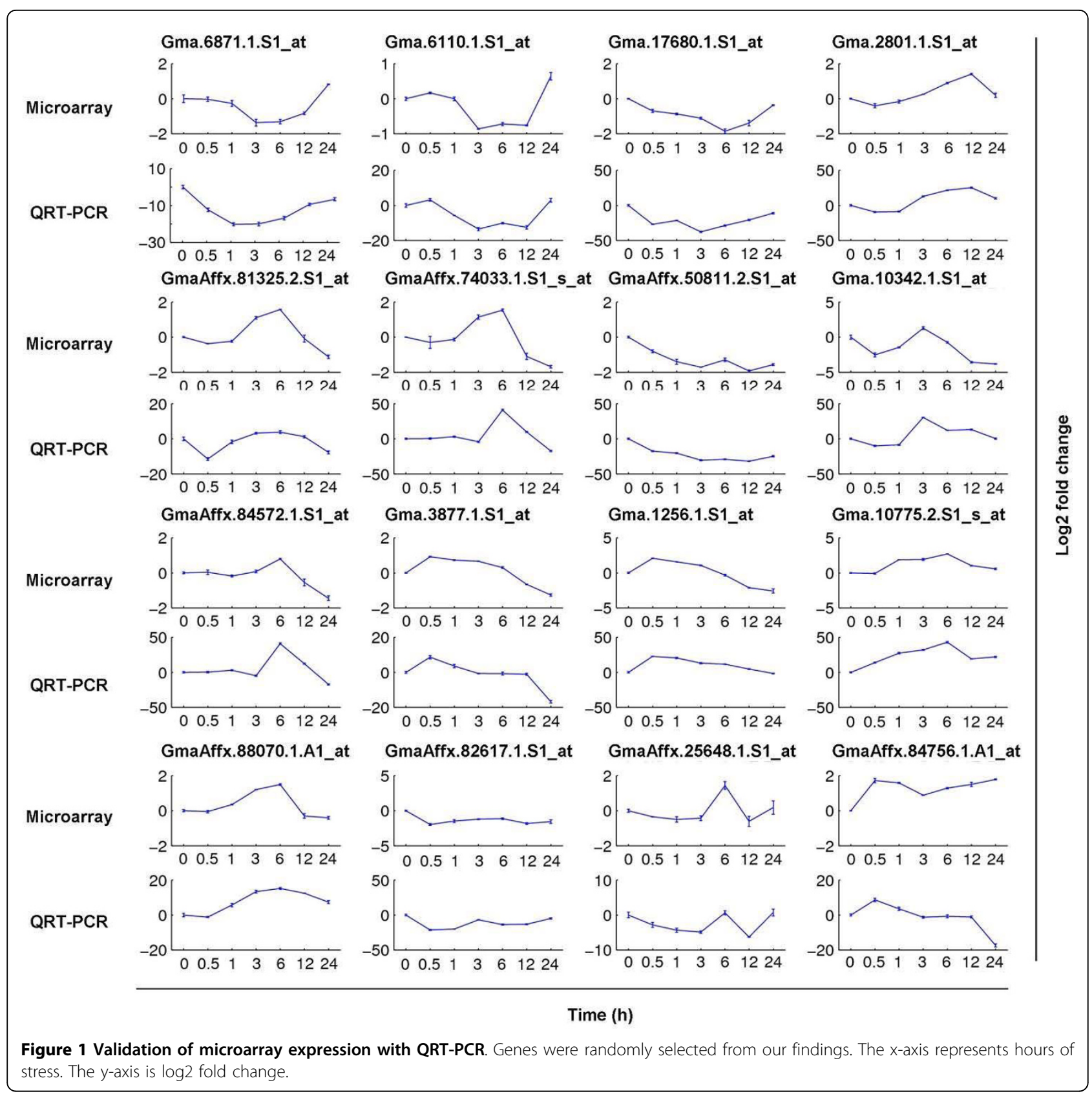

kinase (pepck2), which is nodule-enhanced and regulated throughout nodule development [21]. This protein also increases in response to increasing intracellular $\mathrm{pH}$ in Arabidopsis [22]. The other one (Gma.13972.2.S1 at) encodes an uncharacterised protein containing regulator of chromosome condensation (RCC1) domain. The $\mathrm{RCC} 1$ protein is known to be involved in the maintenance of chromatin conformation, in regulation of chromosome condensation, and in monitoring and signalling of DNA replication [23]. The constant up regulation of this gene, which is similar to Arabidopsis subjected to cold and oxidative stresses [3], indicates that adjustment of chromosome structure is needed under stress condition. The number of specifically down-regulated genes ranged from 45.24 to $61.52 \%$ of total genes at various time points.

\section{Co-expression analysis of stress regulated genes}

Time course analysis using a method described by Storey [24] revealed 1592 probe sets $(\mathrm{q}<0.001)$ displaying significantly changed expression (Additional file 3 ). Hierarchical clustering of averaged expression value from two biological replicates identified 8 distinctive patterns for the 1592 genes (Additional file 4). 


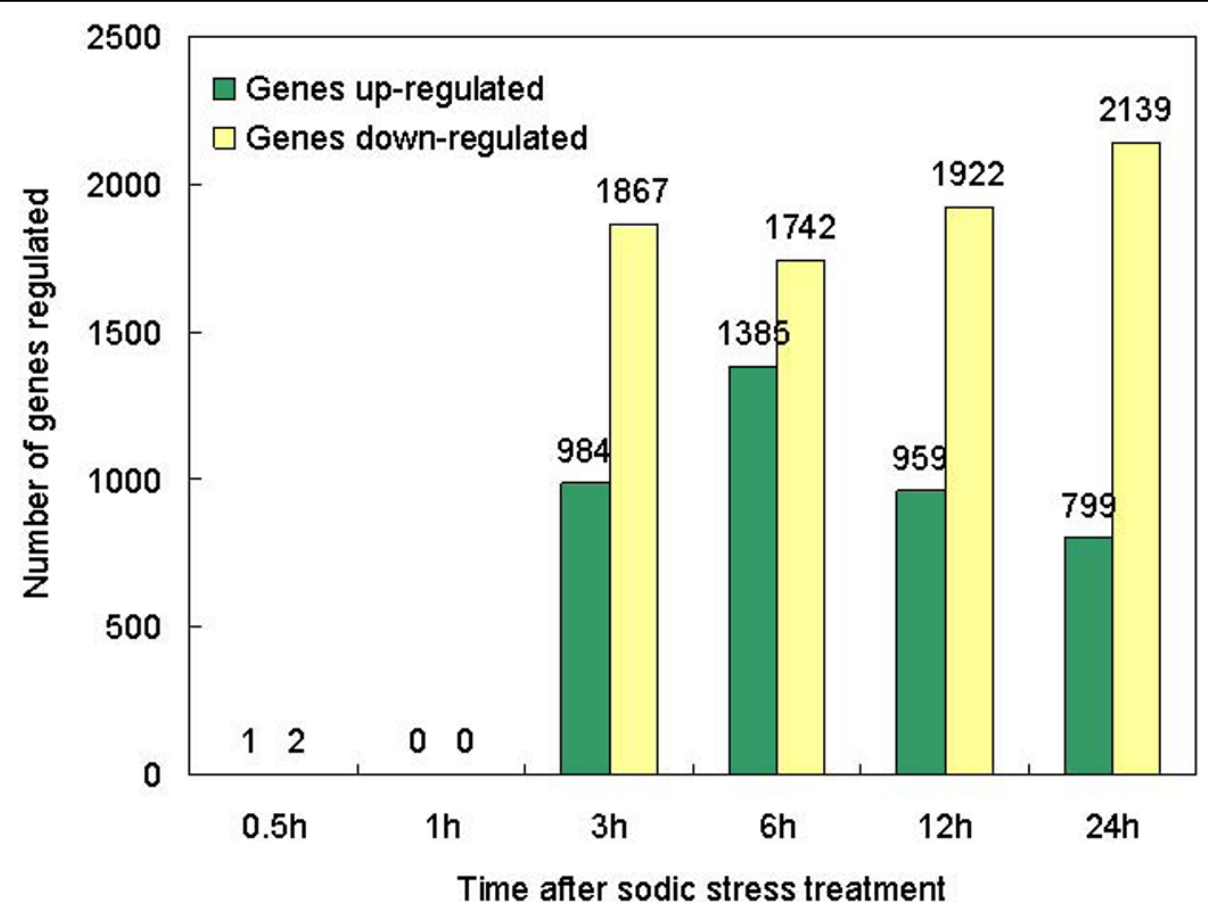

Figure 2 Number of genes differentially expressed in roots under saline-alkaline stress treatment. Total number of genes differentially up- (green bars) and down-regulated (yellow bars) in roots under $50 \mathrm{mmol} / \mathrm{L} \mathrm{NaHCO}$ stress treatment compared with the sample without stress $(P<0.05, q<0.15)$. The $x$-axis represents hours of stress. The $y$-axis represents number of probe sets. The tissues for RNA extraction were harvested at the indicated time points. See Methods for data normalization, processing, statistical analysis and classification of differentially expressed genes.

K-means clustering was conducted to analyze the coexpression setting and 8 clusters with coordinated expression patterns were identified (Figure 4). These clusters reflected the general trends and key transitional states during $\mathrm{NaHCO}_{3}$ stress. Gene lists for each cluster, including normalized expression values, can be found in additional file 5. Clusters I, II and IV contain genes down-regulated after $1 \mathrm{~h}$, but up-regulated at different time points. Differ from the other two Clusters; genes in Cluster IV were down-regulated after $12 \mathrm{~h}$. Clusters III, $\mathrm{V}$ and VIII contain genes up-regulated after $1 \mathrm{~h}$, but down-regulated after $6 \mathrm{~h}$. Genes in Cluster VIII were

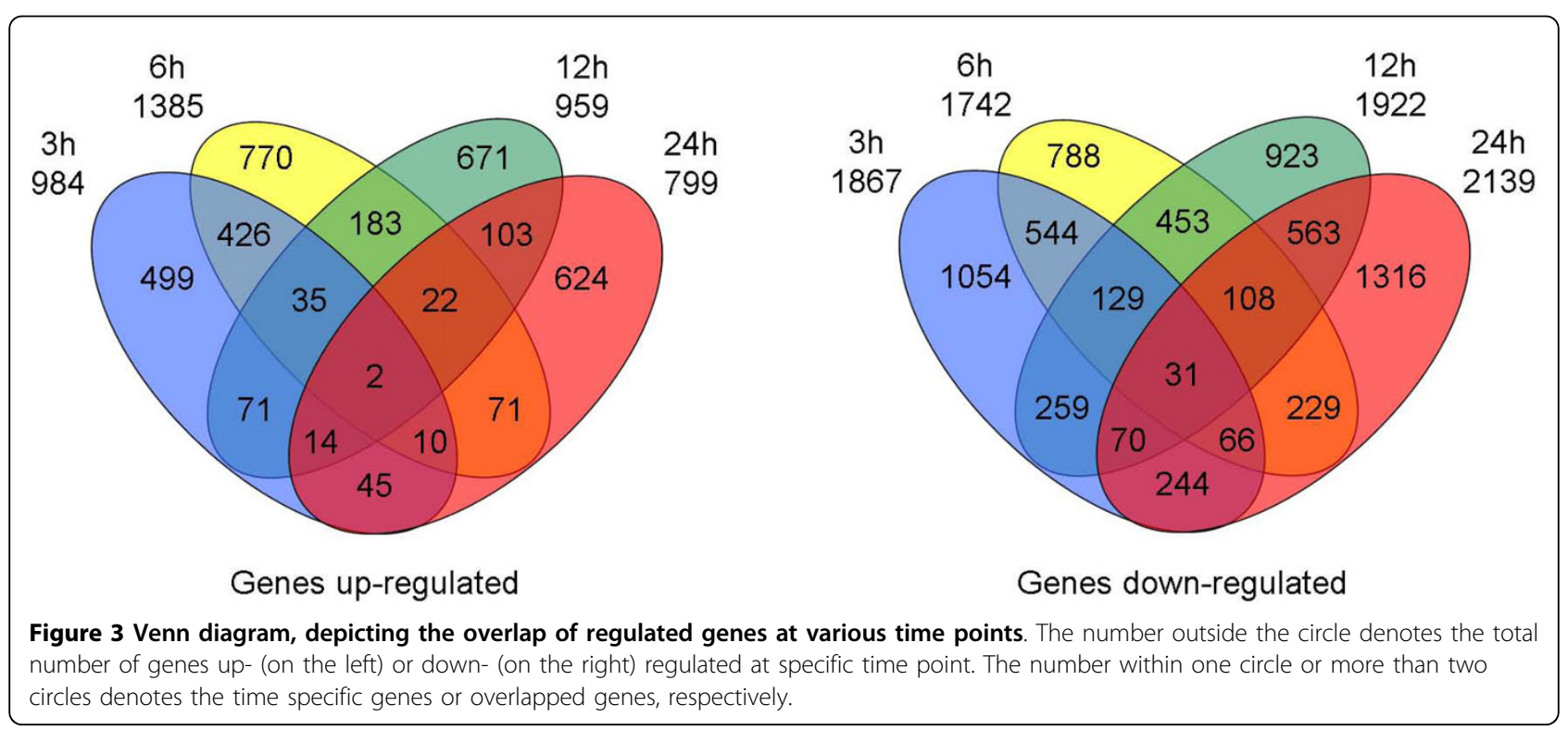



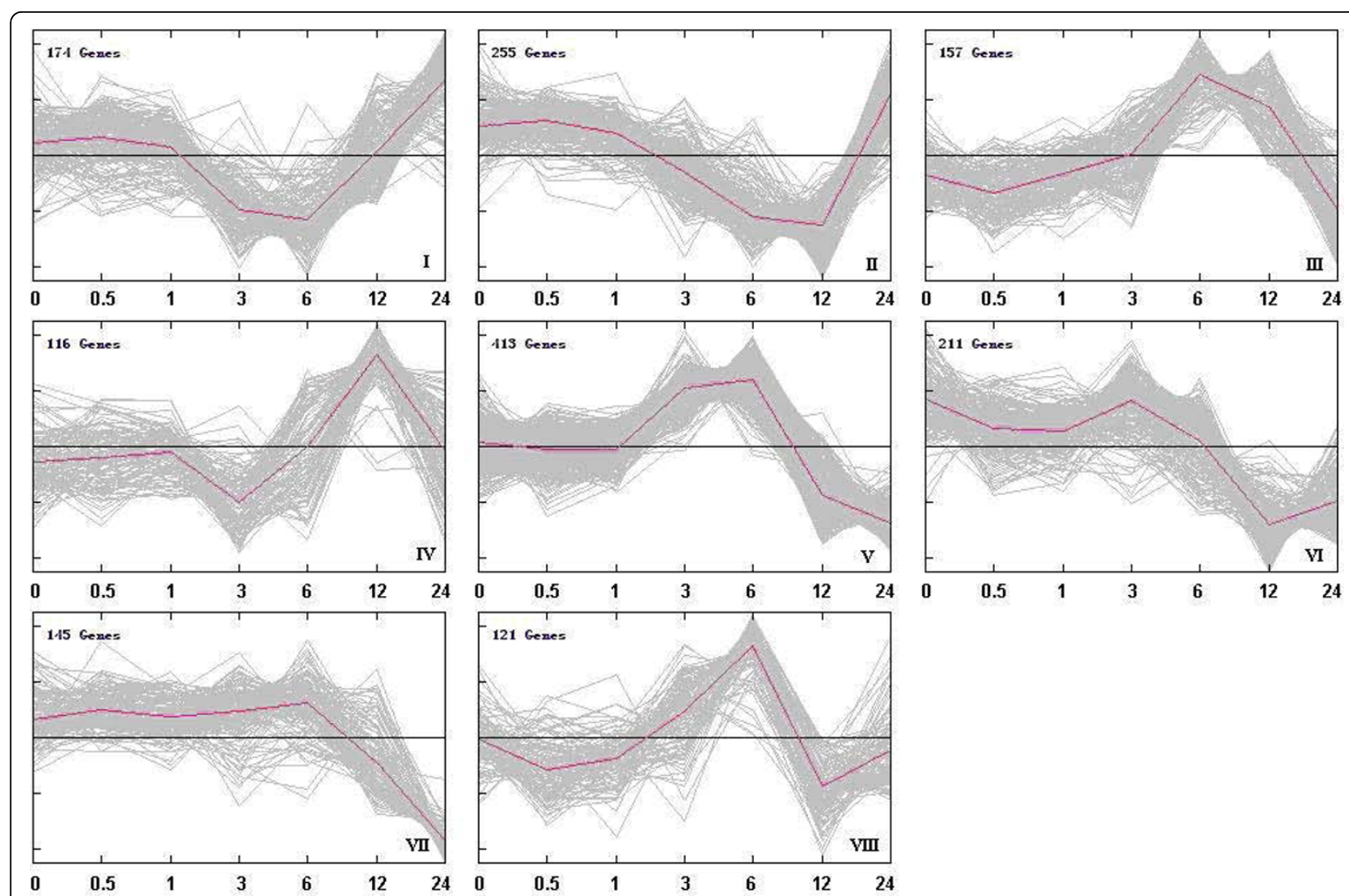

Figure 4 Dynamic expression pattern of different clusters during $\mathrm{NaHCO}_{3}$ stress. Genes with altered expression over time were identified by Edge $[80,81]$ time course methodology (q value $<0.001$ ). K-means clustering was performed to identify 8 clusters, each containing various numbers of genes with similar expression pattern under $\mathrm{NaHCO}_{3}$ stress. The red lines show representative transcriptional regulators. The $\mathrm{x}$-axis represents the stress treatment time in hours. The y-axis represents normalized log2 microarray expression data.

up-regulated after $12 \mathrm{~h}$ and genes in cluster VII exhibited a more dramatic decrease after $6 \mathrm{~h}$. In cluster VI, genes exhibited a minor decrease after $3 \mathrm{~h}$.

\section{Functional categorization and pathway of differentially expressed genes}

Out of the 1592 significantly changed probe sets, we assigned at least one GO term to 1380 probe sets based on sequence similarity. The distribution of functional categories is showed in Figure 5. As seen, 7 GO overrepresented $(\mathrm{P}<0.01, \mathrm{FDR}<0.05)$ categories were: metabolism signal transduction, energy, transcription, secondary metabolism, transporter, disease and defence. These biological processes were affected by the sodic stress treatment.

To understand the relationship between response time points of transcripts and their biology meanings, GO enrichment analysis $(\mathrm{P}<0.05, \mathrm{q}<0.15)$ and MapMan $[25,26]$ visualization were conducted. As illustrated in Figure 6, genes participate in signal transduction and secondary metabolisms were over-represented at earlier time points $(3 \mathrm{~h})$. These secondary metabolisms related genes, which significantly participate in phenylpropanoid, simple phenols, flavonoids, lignin and lignans, and non-mevalonate (MVA) pathway, were presented upregulated under sodic stress (Figure 7). Phenylpropanoid metabolism was found induced under stress (including salt) $[27,28]$. Similar to the signal transduction process, these secondary metabolisms might generate a cascade response for their early induction after stress treatment.

Genes involved in metabolism, secondary metabolism, disease and defence, cell structure, intracellular traffic were induced after $6 \mathrm{~h}$ and genes involved in energy production were decreases after $6 \mathrm{~h}$. Furthermore, genes responsible for signal transduction, transcription and transporter were decreased at later time point $(12 \mathrm{~h})$. Signal transduction and intracellular traffic were decreased at $24 \mathrm{~h}$, while energy was induced. These observations were further supported by a more specific comparison of metabolism using MapMan. This analysis showed up-regulation of several biosynthetic pathways at $6 \mathrm{~h}$, such as terpenes, flavonoids, phenylpropanoids \& phenolics, TCA, sucrose metabolism, lignin and lignans and non-mevalonate (MVA) pathway (Additional file 


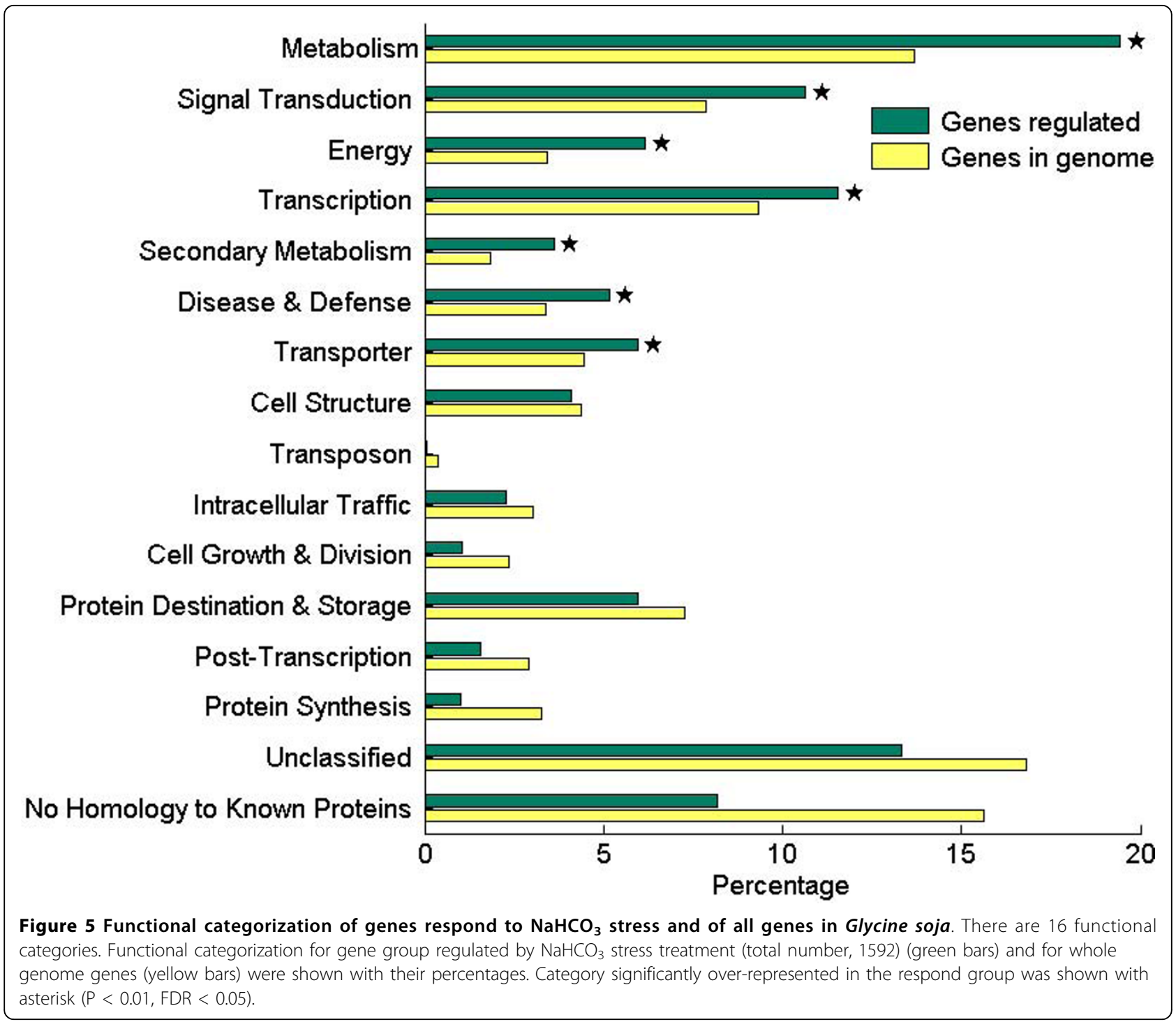

$6 \mathrm{~A})$. The number of genes participate in secondary metabolism were found more at $6 \mathrm{~h}$ than that at $3 \mathrm{~h}$ (Figure 7). A further investigation was done to the JA synthesis (Additional file 6B). It was observed that lipoxygenases and oxophytodienoate reductase were up-regulated at $6 \mathrm{~h}$, indicating that the JA synthesis pathway participates in the early response to sodic stress. Several biosynthetic pathways were down-regulated at $12 \mathrm{~h}$, such as cell wall modification, flavonoids, phenylpropanoids \& phenolics and lipids metabolism pathways (Additional file 6A). A custom MapMan pathway image was generated and AP2-EREBP, WRKY, bZIP, MYB and MYB related, $\mathrm{C} 2 \mathrm{C} 2$ and $\mathrm{C} 2 \mathrm{C} 2-\mathrm{CO}$-like transcript factors were decreased at $12 \mathrm{~h}$ (Additional file 6C and 6D). Protein synthesis were induced after $12 \mathrm{~h}$, and most of them were plastidic, misc and proteins in the nucleotide (Additional file 6E).
The above analysis revealed a cascade process: 1 ) Firstly, signal transduction and secondary metabolism were induced at $3 \mathrm{~h} ; 2$ ) As a result, metabolism, disease defense, cell structure and intracellular traffic were induced at $6 \mathrm{~h}$; 3) After that, signal transduction, transcription and transporter decreased after $12 \mathrm{~h}$; 4) Later on, signal transduction, secondary metabolism and intracellular traffic was induced at $6 \mathrm{~h}$, and decreased at $24 \mathrm{~h}$; 5) After a long period of stress treatment, protein synthesis and energy were induced at $12 \mathrm{~h}$ and $24 \mathrm{~h}$, respectively.

Detailed descriptions of genes participate in signal transduction and transcription are as follows:

\section{Signal transduction}

Approximately, 122 probe sets representing various signalling proteins, such as 14-3-3, protein phosphatase, small 


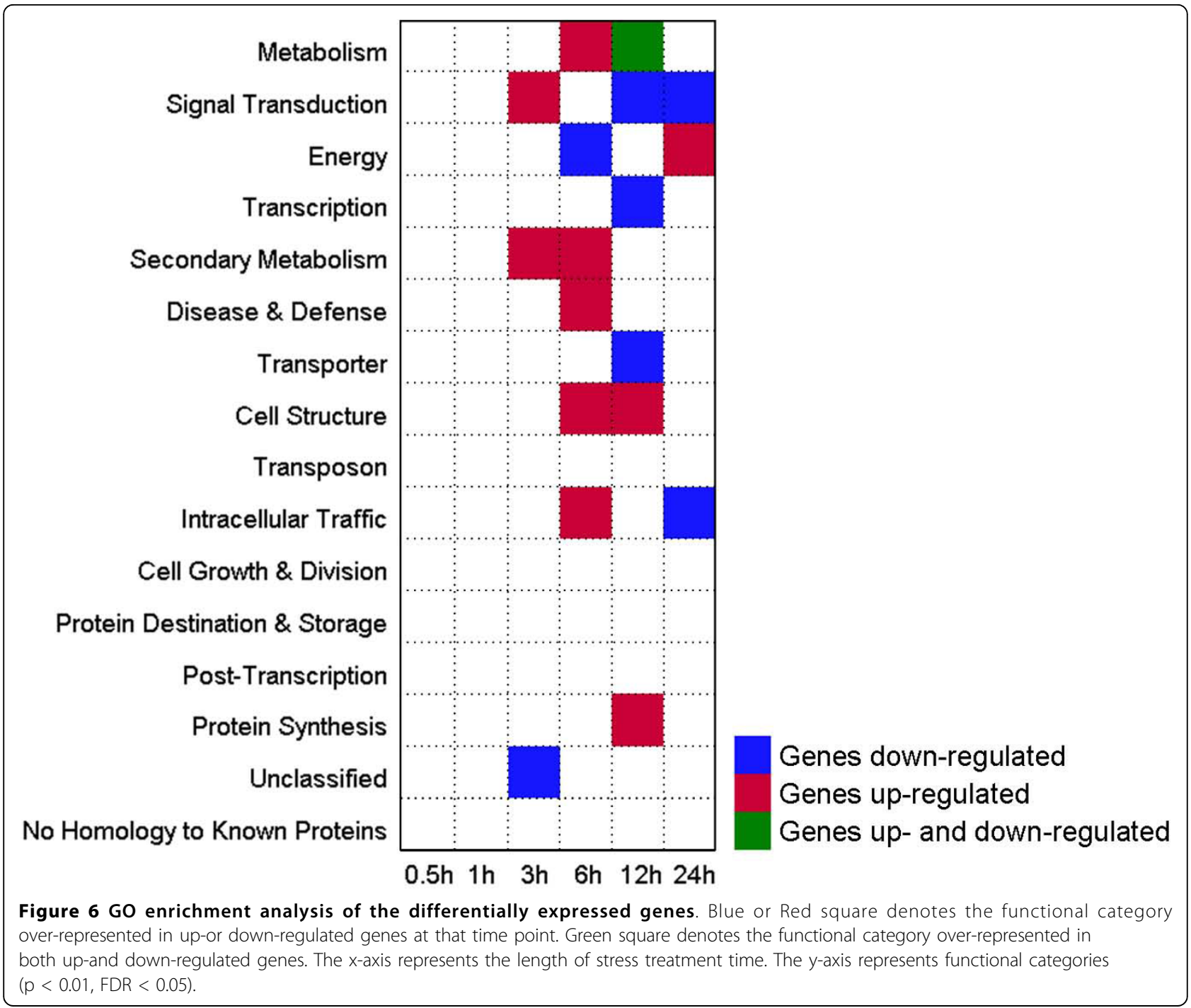

GTPases, and protein kinases, calmodulin-binding family proteins, were up-regulated at $3 \mathrm{~h}$ and down-regulated after $12 \mathrm{~h}$. Stress tolerance or susceptibility in plants is a coordinated action of various genes including those signalling pathway components [29-31]. As expected, protein phosphatase and protein kinase were over-represented at earlier time points because reversible protein phosphorylation is a central mechanism in cellular signal transduction and transcriptional regulation [32]. Calmodulin-binding family protein, such as calcium-dependent protein kinase or calmodulin-like domain protein kinases (CDPKs) are essential sensor-transducers of calcium signalling pathways in plants [33]. Their up-regulation at the early stage endorsed the trigger of downstream components to cope with the stressful condition.

It is noteworthy that members of the 14-3-3 family protein were also up-regulated at the early stage of $\mathrm{NaHCO}_{3}$ stress. 14-3-3 family proteins, for its specific phosphoserine/phosphothreonine-binding activity [34], are thought to be involved in a large range of abiotic signalling processes and to interact with many regulatory proteins like transcription factors, plasma membrane $\mathrm{H}^{+}$-ATPase, ion channels, ascorbate peroxidase (APX) and abscisic acid (ABA) [35-38].

\section{Transcription factors}

As above, two processes, transcription and transport, emerged at earlier time points. Probe sets up-regulated before $6 \mathrm{~h}$ were listed in Additional file 7. According to the putative annotation assigned by homology search with genes in Arabidopsis Gene Regulatory Information Server [39,40], 147 transcription factors representing 29 different families were found to be induced at earlier stage of stress treatment ( $3 \mathrm{~h}$ and $6 \mathrm{~h}$ ). These transcription factor families were compared (Figure 8) to identify families playing main roles at earlier stress response. 


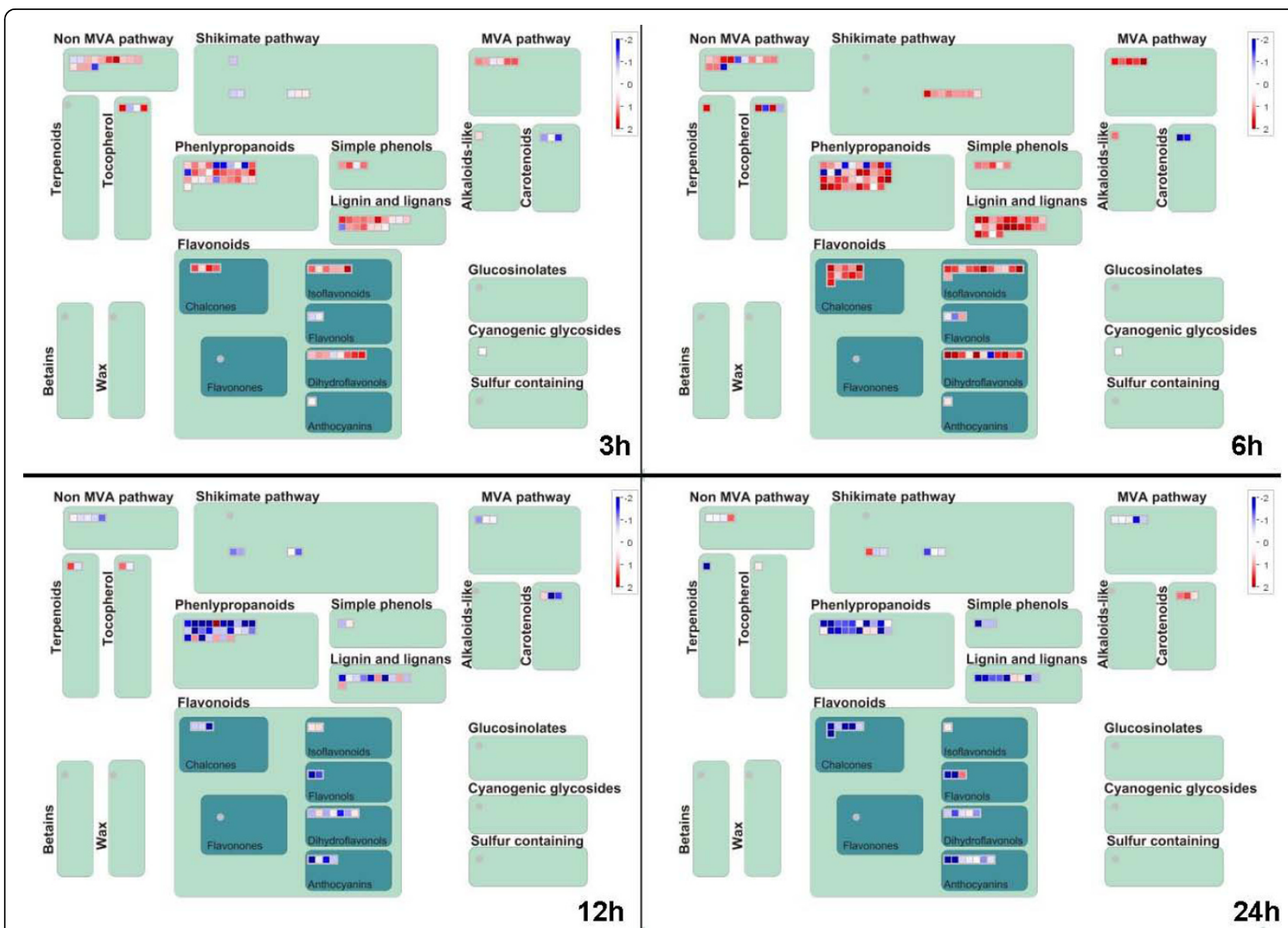

Figure 7 Genes up/down regulated in the overview of secondary metabolism. Mapman was used to visualize the secondary metabolism pathways with genes up/down regulated at $3 \mathrm{~h}, 6 \mathrm{~h}, 12 \mathrm{~h}$, and $24 \mathrm{~h}$. In the display, each BIN or subBIN is represented as a block where each transcript is displayed as a square, which is either colored red if this transcript is up- or blue if this transcript is down-regulated.

Plant WRKY transcription factor superfamily are known to be involved in biotic [41] and abiotic stress [4] response, and in developmental processes [42]. However, their roles in mediating plant alkaline stress response are largely unknown. Recently, 64 GmWRKY genes were identified from soybean [43], and 30 probe sets representing 15 WRKY family members were quickly induced at early time point before decreasing at later time points. This pattern was similar to WRKYs expression pattern in response to other biotic or abiotic stresses in numerous plant species [42].

Similar to the WRKY superfamily, AP2-EREBP family are well known for their important functions in plant growth and development, especially in hormonal regulation and in environmental stress response $[43,44]$. Our results showed that transcripts encoding AP2-EREBP family proteins increased drastically after $3 \mathrm{~h}$, and rapidly decreased after $12 \mathrm{~h}$ of stress treatment.

Although a member of GRAS family proteins seems to be involved in development and other processes, such as rhizobial Nod factor-induce [45], SHORT-ROOT movement[46], GA3 induction [47] and drought stress [48], very little is known about their physiological roles under saline or alkaline stress. The stress modulated expression of GRAS genes suggested they may be important in $\mathrm{NaHCO}_{3}$ stress response. A full list of GRAS family proteins in soybean still needs to be identified systematically.

In addition, the BZR1 and BES1 protein regulate subsets of BR-responsive genes as downstream signalling components [49] and are considered to mediate responses to other stimuli as well. The ethylene-insensitive3-like (EIL) transcription factor, which participates in ethylene signalling pathway [50], was also induced at the early stage of $\mathrm{NaHCO}_{3}$ stress treatment.

14-3-3 proteins are known to regulate several cellular processes and therefore are called as General Regulatory Factors (GRFs) [51]. We found that GRF family genes were up-regulated from 0.5 to $6 \mathrm{~h}$, and decreased after $12 \mathrm{~h}$. Recent investigation of 14-3-3 gene expression 


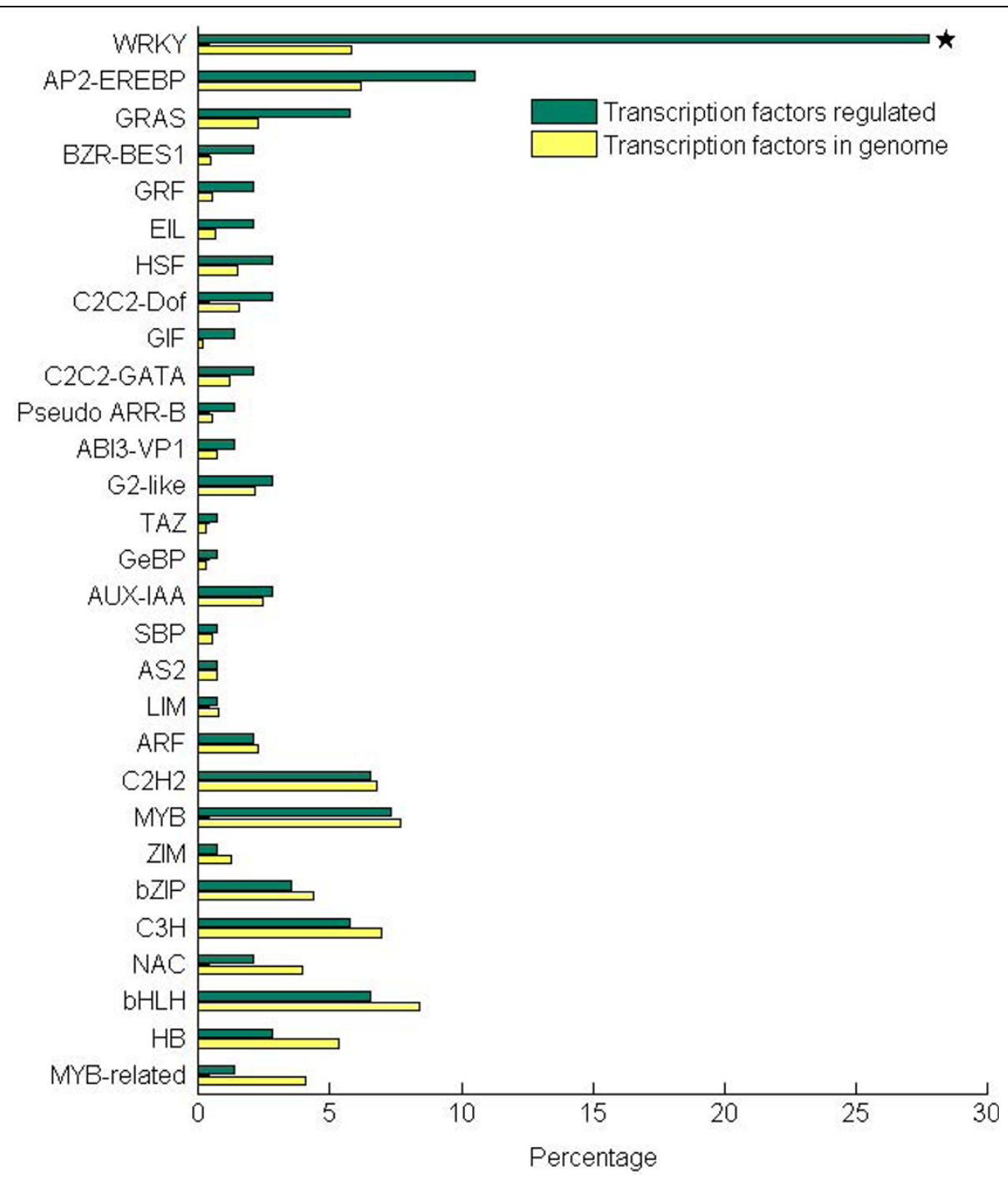

Figure 8 Transcription factors families of the up-regulated genes at the early stage of $\mathbf{N a H C O}_{3}$ treatment. There are 29 transcription factors families. Transcription factors families for gene group induced at $3 \mathrm{~h}$ and $6 \mathrm{~h}$ of $\mathrm{NaHCO}_{3}$ stress treatment (total number, 147) (green bars) and for whole genome genes (yellow bars) were shown with their percentages. Transcription factors family significantly over-represented in the respond group was shown with asterisk $(P<0.01, F D R<0.05)$.

profile showed that they are also regulated by salt stress [52-54] and alkaline stress [11,12].

\section{MicroRNAs}

Several stress-specific microRNAs have been identified in plants under various abiotic stresses, including nutrient deficiency $[55,56]$, drought $[57,58]$, cold [59], high salinity [58,60,61], UV-B radiation [62] and mechanical stress [63]. Some microRNA targets are stress-related genes, suggesting that microRNAs play important roles in plant stress response [64].

A BLASTn [65] search against 78 pre-microRNAs in miRBase (Release 13.0, March 2009) [66-69] identified 30 microRNAs in the microarray, among which 11 were called Present and were modulated by $\mathrm{NaHCO}_{3}$ stress. Hierarchical clustering using the average expression value of these 11 microRNAs identified 4 distinctive patterns as illustrated in Figure 9. MiR398, miR1507a, miR1507b and miR156a were reduced after $3 \mathrm{~h}$ and increased after $12 \mathrm{~h}$. Mir398 targets two $\mathrm{Cu} / \mathrm{Zn}$ superoxide dismutases (CSD1 and CSD2) and was reported to decrease dramatically under oxidative stress in Arabidopsis [70]. MiR156a was increased under salt stress in Arabidopsis, and targets 2 SBP family transcription factors which play essential role in vegetative phase change and root development [59]. MiR1507a and miR1507b were known to be involved in nitrogen fixation in soybean nitrogen-fixing nodules [71]. Similar to the 


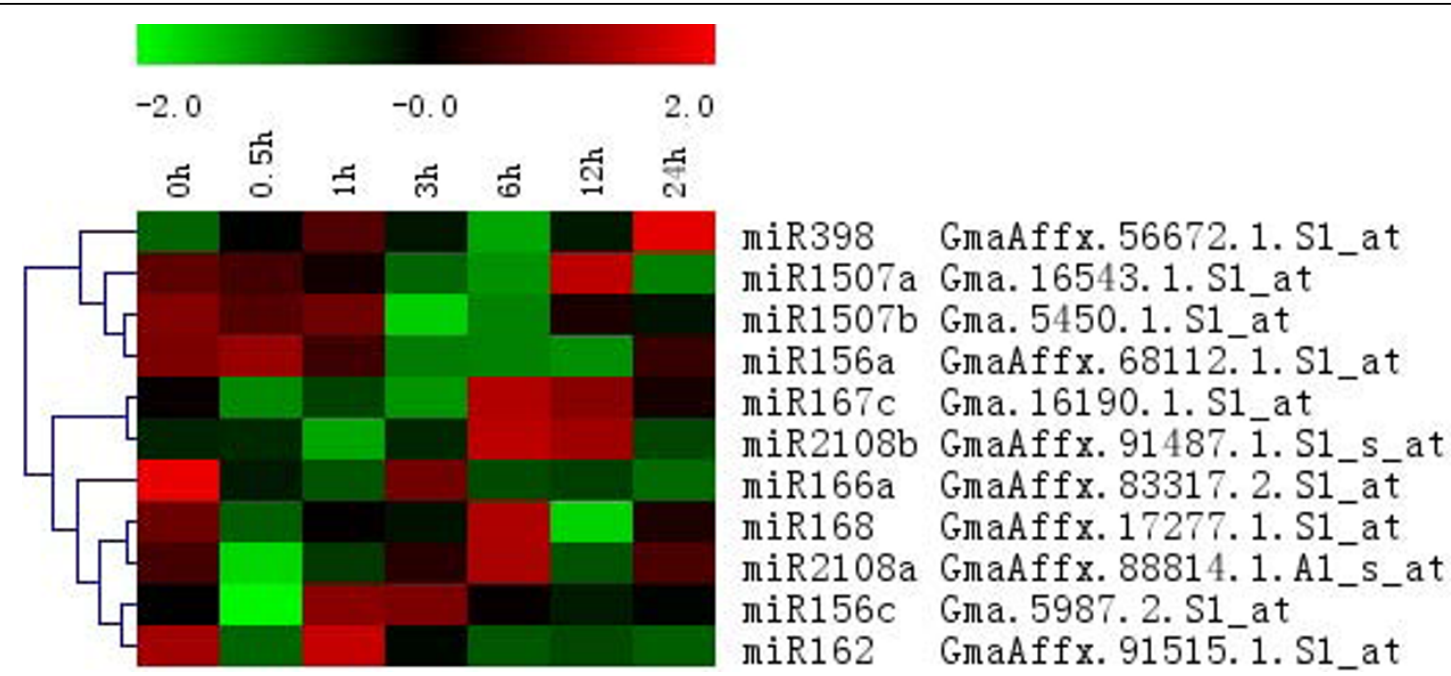

Figure 9 Expression profile of pre-microRNAs under $\mathrm{NaHCO}_{3}$ stress. The pre-microRNAs probe sets were annotated with the predicted microRNAs. Pearson correlation Hierarchical clustering of averaged expression value from two biological replicates was shown.

observation in Arabidopsis [59], MiR167c and miR2108b were significantly up-regulated at $6 \mathrm{~h}$. MiR166a, miR168 and miR2108a form a cluster with distinctive dynamic pattern (decreased after $0.5 \mathrm{~h}$, followed by an increase after $3 \mathrm{~h}$ before a decrease after $6 \mathrm{~h}$ ). MiR168 has been reported to be salt stress regulated and target to ARGONAUTE1, which is related to plant development $[59,72]$. The stress modulated miRNAs suggest their possible roles in alkaline stress.

\section{Conclusions}

This is the first comprehensive transcriptome profiling analysis of wild soybean root under alkaline stress. The current knowledge about plant alkaline stress response is limited and we provide a list of genes showing dynamic expression change under $\mathrm{NaHCO}_{3}$ stress. Functional characterization of these genes highlights the common and distinctive mechanisms underlying plant response to alkaline and other abiotic stress. Most of the alkaline-modulated genes are involved in metabolism, energy, signal transduction and transcription. Some molecular processes, such as signal transduction, secondary metabolism, and regulation of transcription, were induced at earlier time points. Genes involved in these processes accomplished their regulatory mission and decreased after $12 \mathrm{~h}$. As a result, protein synthesis and energy metabolism were induced. These data indicate that the cellular pathways respond to the $\mathrm{NaHCO}_{3}$ stress as a cascade process.

\section{Methods}

Plant material, growth conditions, and stress treatments Glycine soja L. seeds were grown in a culture room with the following settings: $60 \%$ relative humidity, $24^{\circ} \mathrm{C}$ and a light regime of $16 \mathrm{~h}$ light/ $8 \mathrm{~h}$ dark. The light source SON-T ARGO $400 \mathrm{~W}$ generated constant illumination of $30000 \mathrm{~lx}$. Before sowing, seeds of Glycine soja L. G07256 were shaken for $10 \mathrm{~min}$ in $98 \%$ sulfuric acid. Subsequently, seeds were washed five times with sterile water. Thirty seeds were placed on each petri dish to accelerate germination for 2 days. Germinated seedlings were then transferred into the growth boxes containing 1/4 strength Hoagland's solution. Nineteen days after sowing, seedlings in the stress treatment group were transferred into $1 / 4$ strength Hoagland's solution with $50 \mathrm{mmol} / \mathrm{L} \mathrm{NaHCO}_{3}(\mathrm{pH}$ 8.5) before exposure to light condition for $3 \mathrm{~h}$.

\section{Tissue harvest and RNA isolation}

Roots from $3 \mathrm{~cm}$ root apex were harvested in two independent biological replicates after $0,0.5,1,3,6,12$ and $24 \mathrm{~h}$ treatment with $50 \mathrm{mmol} / \mathrm{L} \mathrm{NaHCO}_{3}$ stress under the same light condition. Samples were immediately frozen in liquid nitrogen, and stored at $-80^{\circ} \mathrm{C}$. To minimize biological variance, roots from three plants originating from the same experiment, condition and cultivar were pooled, and the extracted RNA was used for microarray hybridization. Total RNA was extracted from frozen roots with TRIzol (Invitrogen, Carlsbad, CA) according to the instructions from the manufacturer. RNA integrity was evaluated on agarose gels electrophoresis and absorbance $260 / 280$ ratios between 1.8 and 2.2 were typically obtained.

For QRT-PCR experiments, reverse transcription was carried out using the SuperScript ${ }^{\oplus}$ III First-Strand Synthesis System (SKU\# 18080-051, Invitrogen) according to the manufacturer's instructions. Prior to the QRT-PCR assays, the quality of the cDNA was assessed by PCR 
with gapdh-specific primers to test for genomic DNA contamination.

\section{DNA chip hybridization}

GeneChip Soybean Genome Array (Cat. \# 900526; Affymetrix ; Santa Clara, CA, USA) containing 37,744 Glycine max probe sets $(35,611$ transcripts) was used for microarray analysis. This high-density array consists of 11-probe pair ( 25 bp per oligonucleotide) and provides multiple independent measurements for each individual transcript. cDNA labelling and Affymetrix ${ }^{\bullet}$ hybridization was carried out by Gene Tech Biotechnology Company Limited (Shanghai, China) according to a Affymetrix ${ }^{\circ}$ protocol (Affymetrix ${ }^{\circ}$, Santa Clara, CA) outlined in [73].

\section{Microarray Data Analysis}

The computation of expression values were conducted using dChip software [74] (Cheng Li Lab, Harvard). We adopted a sample wise normalization to the median probe cell intensity (CEL) of all 14 arrays. For each sample, the median CEL intensity of one replicate was scaled to the median CEL intensity of all arrays and defined as baseline. The remaining replicates of each sample were normalized to the baseline applying an Invariant Set Normalization Method [75]. Model-based gene expression was obtained from normalized CEL intensities based on a Perfect Match-only model [75]. The quality of each repeated experiment was tested by performing a Pearson's Correlation of signal intensities. Present/Absent/ Marginal calls were generated from scanned arrays using Affymetrix $^{\oplus}$ GCOS 1.4 software. Only genes present at least in one of the two biological replicates of each time point were considered as Present [76].

Two types of analysis were conducted to identify differentially expressed genes. First, two-sample t-test was used to evaluate differential expression of genes between each time point $(\mathrm{P}<0.05)$ [77]. The data were further filtered based on the False Discovery Rate (FDR, q value $<0.15)[78,79]$. Second, Edge $[80,81]$ time course methodology was used to test for genes with changed expression changes over time (q value $<0.001$ ). Hour was chosen for class variable and covariate giving time points; Differential Expression Type was Time course; Spline type was Natural cubic spline.

Pearson correlation Hierarchical Clustering and KMeans Clustering were performed with TM4: MeV 4.3 $[82,83]$. Details of the GeneChip soybean genome array are available at the Affymetrix website [84]. The annotation and functional categories for these transcripts were assigned based on the Soybean GeneChip annotation file (Updated Oct. 2007) and Arabidopsis ATH1 array annotation file (Updated Sept. 2007) [85]. To assess the significance of over-represented GO terms or the transcription factor families in the list of the regulated genes against the genome, Fisher's Exact Test $(\mathrm{p}<0.01)$ [86] and Benjamini and Hochberg method (FDR < 0.05) [79] were used. The visualization of profiling data sets in the context of existing knowledge (pathway) was performed with MapMan $[23,24]$. The mapping file is Gmax_AFFY_09 (1.0).

\section{Real-time quantitative PCR}

The glyceraldehyde-3-phosphate dehydrogenase (gapdh, AFFX-r2-Gma-gapdh-M_at, accession \# DQ355800) was used to normalize all values in the QRT-PCR assays, because it exhibited the lowest variation in expression values throughout the $\mathrm{NaHCO}_{3}$ treatment (average fold change $=1.096$, coefficient of variation $=0.114$ ). Primers for QRT-PCR were designed using Primer3 software [87]. Primer sequences were listed in Additional file 8.

QRT-PCR reactions based on SYBR Green fluorescence were performed using SYBR GreenER ${ }^{\mathrm{Tu}}$ using qPCR SuperMix Universal (SKU\# 11762-500, Invitrogen) on a Bio-rad iQ5 Real-Time PCR Detection System with $\mathrm{iQ}^{\mathrm{m} w} 5$ Optical System Software Version 2.0 (BIO-RAD, HERCULES, CA, USA) following the manufacturer's instructions. One microliter of synthesized cDNA (diluted 1:10) was used as template. The preset cycling parameters for a SYBR Green experiment with a dissociation curve were used. The analysis term settings were set at an amplification-based threshold, an adaptive baseline, and a moving average. The amplification efficiencies were determined by analyzing the standard curves generated from triplicate series of five cDNA template dilutions. The $\mathrm{iQ}^{\mathrm{tw}} 5$ Optical System Software Version 2.0 plotted the known starting quantities against the measured $\mathrm{Ct}$ values and generate the standard curve. The amplification reactions were consisted of a 2-min denaturing step at $95^{\circ} \mathrm{C}$, followed by 40 cycles at $95^{\circ} \mathrm{C}$ for $10 \mathrm{~s}, 60^{\circ} \mathrm{C}$ for $30 \mathrm{~s}$ and $70^{\circ} \mathrm{C}$ for $30 \mathrm{~s}$, end with melting curve program $70^{\circ} \mathrm{C}$ for $30 \mathrm{~s}$. Three replicate reactions per sample were used to ensure statistical significance. The RNA from each sample was analyzed simultaneously. Expression levels for all candidate genes were computed based on the stable expression level of the reference gene according to Pfaffl method [88].

\section{Additional material}

Additional file 1: Assessment of the replicated experiments using Pearson's correlation analysis. $X$ and $Y$-axis represent the two replicates at each time point. The colour of each square denotes the Pearson's correlation coefficient of the two experiments as indicated in the legend.

Additional file 2: Differentially expressed genes at each time point after $\mathrm{NaHCO}_{3}$ stress. Total number of genes differentially up- and down-regulated in roots under $50 \mathrm{mmol} / \mathrm{L} \mathrm{NaHCO} 3$ stress treatment compared with the sample without stress $(P<0.05, q<0.15)$. The Probe sets were annotated based on the Soybean GeneChip annotation file (Updated Oct. 2007). The fold value was counted using the average expression value between the sample after stress and control. 
Additional file 3: Differentially expressed genes throughout the $\mathrm{NaHCO}_{3}$ stress period. Time course analysis revealed 1592 probe sets ( $q<0.001)$ displaying significantly changed expression. Rank was ordered by Q-value.

Additional file 4: Hierarchical cluster analysis of genes differential expressed throughout the $\mathrm{NaHCO}_{3}$ stress period. Pearson correlation Hierarchical clustering of averaged expression value from two biological replicates was shown.

Additional file 5: List of genes in each cluster from K-means clustering. Pearson correlation K-Means Clustering of averaged expression value from two biological replicates was shown.

Additional file 6: Pathway visualized with MapMan. Pathways up/ down regulated at $3 \mathrm{~h}, 6 \mathrm{~h}, 12 \mathrm{~h}$, and $24 \mathrm{~h}$ were shown.

Additional file 7: Probe sets up-regulated at certain time point before $6 \mathbf{h ~ N a H C O}{ }_{3}$ stress. Probe sets significantly up-regulated at 0.5 $\mathrm{h}, 1 \mathrm{~h}, 3 \mathrm{~h}$ or $6 \mathrm{~h}$ under $50 \mathrm{mmol} / \mathrm{L} \mathrm{NaHCO}_{3}$ stress treatment were listed $(P<0.05, q<0.15)$.

Additional file 8: Genes and primer sequences used in the QRT-PCR assays. Genes, their primer sequences and their sodic stress response patterns were listed.

\section{Acknowledgements}

This project was supported by grant from National Natural Science Foundation of China (30570990), the Key Research Plan of Heilongjiang Province (GB05B104), the Innovation Research Group of NEAU (CXT004), the "863" project (2006AA100104-18) and University Grants Committee, Hong Kong UGC AoE plant Agricultural Biotechnology Project (AoE B-07/09).

\section{Author details}

${ }^{1}$ Plant Bioengineering Laboratory, The College of Life Sciences, Northeast Agricultural University, Harbin, China. ${ }^{2}$ State Key Lab for Agrobiotechnology and Department of Biology, The Chinese University of Hong Kong, Shatin, N. T., Hong Kong.

\section{Authors' contributions}

YG conceived of the study, participated in its design, carried out the material preparation, microarray data analysis and drafted the manuscript, participated in QRT-PCR. YL conceived of the study, participated in its design and assisted with statistical analysis. XB participated in its design and coordination. DKL assisted with the program composition and pre-microRNA prediction. WJ participated in QRT-PCR. HC participated in its coordination. YMZ and DJG conceived of the study, participated in its design and coordination, and helped with the manuscript editing. All authors read and approved the final manuscript.

\section{Received: 25 November 2009 Accepted: 26 July 2010}

Published: 26 July 2010

\section{References}

1. Jiang Y, Deyholos MK: Comprehensive transcriptional profiling of $\mathrm{NaCl}-$ stressed Arabidopsis roots reveals novel classes of responsive genes. BMC Plant Biology 2006, 6:25.

2. Ge Y, Zhu YM, Lv DK, Dong TT, Wang WS, Tan SJ, Liu CH, Zou P: Research on responses of wild soybean to alkaline stress. Pratacultural Science 2009, 26(2):47-52.

3. Kilian J, Whitehead D, Horak J, Wanke D, Wein S, Batistic O, D'Angelo C, Bornberg-Bauer E, Kudla J, Harter K: The AtGenExpress global stress expression data set: protocols, evaluation and model data analysis of UV-B light, drought and cold stress responses. Plant Journal 2007, 50(2):347-363.

4. Seki M, Narusaka M, Ishida J, Nanjo T, Fujita M, Oono Y, Kamiya A, Nakajima M, Enju A, Sakurai T: Monitoring the expression profiles of 7000 Arabidopsis genes under drought, cold and high-salinity stresses using a full-length cDNA microarray. Plant Journal 2002, 31(3):279-292.

5. Takahashi S, Seki M, Ishida J, Satou M, Sakurai T, Narusaka M, Kamiya A, Nakajima M, Enju A, Akiyama K: Monitoring the expression profiles of genes induced by hyperosmotic, high salinity, and oxidative stress and abscisic acid treatment in Arabidopsis cell culture using a full-length cDNA microarray. Plant Molecular Biology 2004, 56:29-55.

6. Kawasaki S, Borchert C, Deyholos M, Wang H, Brazille S, Kawai K, Galbraith D, Bohnert HJ: Gene expression profiles during the initial phase of salt stress in rice. Plant Cell Online 2001, 13:889-906.

7. Kawaura K, Mochida K, Yamazaki Y, Ogihara Y: Transcriptome analysis of salinity stress responses in common wheat using a $22 \mathrm{k}$ oligo-DNA microarray. Functional \& Integrative Genomics 2006, 6(2):132-142.

8. Kawaura K, Mochida K, Ogihara Y: Genome-wide analysis for identification of salt-responsive genes in common wheat. Functional \& Integrative Genomics 2008, 8(3):277-286.

9. Tattersall E, Grimplet J, DeLuC L, Wheatley M, Vincent D, Osborne C, Ergül A, Lomen E, Blank R, Schlauch $\mathrm{K}$, et al: Transcript abundance profiles reveal larger and more complex responses of grapevine to chilling compared to osmotic and salinity stress. Functional \& Integrative Genomics 2007, 7(4):317-333.

10. Irsigler A, Costa M, Zhang P, Reis P, Dewey R, Boston R, Fontes E: Expression profiling on soybean leaves reveals integration of ER- and osmotic-stress pathways. BMC Genomics 2007, 8:431

11. Jin H, Plaha P, Park JY, Hong CP, Lee IS, Yang ZH, Jiang GB, Kwak SS, Liu SK, Lee JS, Kim YA, Lim YP: Comparative EST profiles of leaf and root of Leymus chinensis, a xerophilous grass adapted to high $\mathrm{pH}$ sodic soil. Plant Science 2006, 170(6):1081-1086.

12. Wang Y, Yang C, Liu G, Zhang G, Ban Q: Microarray and suppression subtractive hybridization analyses of gene expression in Puccinellia tenuiora after exposure to $\mathrm{NaHCO}_{3}$. Plant Science 2007, 173(3):309-320,

13. Wang Y, Yang C, Liu G, Jiang J: Development of a CDNA microarray to identify gene expression of Puccinellia tenuiora under saline-alkali stress. Plant Physiology And Biochemistry 2007, 45(8):567-576.

14. Wang $Y, M a ~ H$, Liu G, Xu C, Zhang D, Ban Q: Analysis of gene expression profile of Limonium bicolor under $\mathrm{NaHCO}_{3}$ stress using CDNA microarray. Plant Molecular Biology Reporter 2008, 26(3):241-254.

15. Li H, Wang Y, Jiang J, Liu G, Gao C, Yang C: Identification of genes responsive to salt stress on Tamarix hispida roots. Gene 2009, 433(12):65-71.

16. Oshlack A, Chabot A, Smyth G, Gilad Y: Using DNA microarrays to study gene expression in closely related species. Bioinformatics 2007, 23(10):1235-1242.

17. Ji W, Li Y, Li J, Dai C, Wang X, Bai X, Cai H, Yang L, Zhu Y: Generation and analysis of expressed sequence tags from $\mathrm{NaCl}$-treated Glycine soja. BMC Plant Biology 2006, 6:4.

18. Edgar R, Domrachev M, Lash AE: Gene Expression Omnibus: NCBI gene expression and hybridization array data repository. Nucl Acids Res 2002, 30:207-210.

19. Janes K, Gaudet S, Albeck J, Nielsen U, Lauffenburger D, Sorger P: The response of human epithelial cells to TNF involves an inducible autocrine cascade. Cell 2006, 124(6):1225-1239.

20. Busch H, Camacho-Trullio D, Rogon Z, Breuhahn K, Angel P, Eils R, Szabowski A: Gene network dynamics controlling keratinocyte migration. 2008.

21. Xu W, Sato S, Clemente T, Chollet R: The PEP-carboxylase kinase gene family in Glycine max (GmPpcK1-4): an in-depth molecular analysis with nodulated, non-transgenic and transgenic plants. Plant Journal 2007, 49(5):910-923.

22. Chen Z, Jenkins G, Nimmo H: pH and carbon supply control the expression of phosphoenolpyruvate carboxylase kinase genes in Arabidopsis thaliana. Plant, Cell \& Environment 2008, 31(12):1844-1850.

23. Enoch T, Nurse P: Mutation of fission yeast cell cycle control genes abolishes dependence of mitosis on DNA replication. Cell 1990, 60(4):665-673.

24. Storey JD, Xiao W, Leek JT, Tompkins RG, Davis RW: Significance analysis of time course microarray experiments. Proceedings of the National Academy of Sciences of the United States of America 2005, 102(36):12837-12842.

25. Thimm O, Blasing O, Gibon Y, Nagel A, Meyer S, Kruger P, Selbig J, Muller L, Rhee $S$, Stitt M: MAPMAN: a user-driven tool to display genomics data sets onto diagrams of metabolic pathways and other biological processes. Plant Journal 2004, 37(6):914.

26. Usadel B, Nagel A, Thimm O, Redestig H, Blaesing OE, Palacios-Rojas N, Selbig J, Hannemann J, Piques MC, Steinhauser D, Scheible WR, Gibon Y, Morcuende R, Weicht D, Meyer S, Stitt M: Extension of the Visualization 
Tool MapMan to Allow Statistical Analysis of Arrays, Display of Coresponding Genes, and Comparison with Known Responses. Plant Physiol 2005, 138(3):1195-1204.

27. Societies $A$ : Contrasting response mechanisms to root-zone salinity in three co-occurring Mediterranean woody evergreens: a physiological and biochemical study. Functional Plant Biology 2009, 36(6):551-563.

28. Dixon R, Paiva N: Stress-induced phenylpropanoid metabolism. The Plant Cell 1995, 7(7):1085.

29. Xiong L, Schumaker K, Zhu J: Cell signaling during cold, drought, and salt stress. Plant Cell Online 2002, 14:165-183.

30. Yamaguchi-Shinozaki K, Shinozaki K: Transcriptional regulatory networks in cellular responses and tolerance to dehydration and cold stresses. Annual Review of Plant Biology 2006, 57:781-803.

31. Mahajan S, Pandey G, Tuteja N: Calcium-and salt-stress signaling in plants: shedding light on SOS pathway. Archives of biochemistry and biophysics 2008, 471(2):146-158.

32. Ueda A, Li P, Feng Y, Vikram M, Kim S, Kang CH, Kang JS, Bahk JD, Lee SY, Fukuhara T, Staswick PE, Pepper AE, Koiwa H: The Arabidopsis thaliana carboxyl-terminal domain phosphatase-like 2 regulates plant growth, stress and auxin responses. Plant molecular biology 2008, 67(6):683-697.

33. Harper J, Breton $\mathrm{G}$, Harmon A: Decoding $\mathrm{Ca}^{2+}$ signals through plant protein kinases. Annual review of plant biology 2004, 55:263-288.

34. Muslin A, Tanner J, Allen P, Shaw A: Interaction of 14-3-3 with signaling proteins is mediated by the recognition of phosphoserine. Cell 1996, 84(6):889-898.

35. Ferl R, Manak M, Reyes M: The 14-3-3s. Genome Biology 2002, 3(7): reviews3010.1-reviews3010.7.

36. Finnie C, Andersen C, Borch J, Gjetting S, Christensen A, de Boer A, ThordalChristensen $\mathrm{H}$, Collinge D: Do 14-3-3 proteins and plasma membrane $\mathrm{H}$ ${ }^{+}$-ATPases interact in the barley epidermis in response to the barley powdery mildew fungus? Plant molecular biology 2002, 49(2):137-147.

37. Yan J, He C, Wang J, Mao Z, Holaday S, Allen R, Zhang H: Overexpression of the Arabidopsis 14-3-3 protein GF14 lambda in cotton leads to a "stay-green" phenotype and improves stress tolerance under moderate drought conditions. Plant and Cell Physiology 2004, 45(8):1007-1014.

38. Wijngaard P, Sinnige M, Roobeek I, Reumer A, Schoonheim P, Mol J, Wang M, De Boer A: Abscisic acid and 14-3-3 proteins control $\mathrm{K}^{+}$channel activity in barley embryonic root. The Plant Journal 2005, 41:43-55.

39. Arabidopsis Gene Regulatory Information Server. [http://biodatabase.org/ index.php/AGRIS_-_Arabidopsis_Gene_Regulatory_Information_Server].

40. Davuluri R, Sun H, Palaniswamy S, Matthews N, Molina C, Kurtz M, Grotewold E: AGRIS: Arabidopsis gene regulatory information server, an information resource of Arabidopsis cis-regulatory elements and transcription factors. BMC bioinformatics 2003, 4:25.

41. Pandey SP, Somssich IE: The role of WRKY transcription factors in plant immunity. Plant Physiology 2009, 150(4):1648-1655.

42. Ülker B, Somssich I: WRKY transcription factors: from DNA binding towards biological function. Current Opinion in Plant Biology 2004, 7(5):491-498.

43. Zhou Q, Tian A, Zou H, Xie Z, Lei G, Huang J, Wang C, Wang H, Zhang J, Chen S: Soybean WRKY-type transcription factor genes, GmWRKY13, GmWRKY21, and GmWRKY54, confer differential tolerance to abiotic stresses in transgenic Arabidopsis plants. Plant Biotechnology Journal 2008, 6(5):486-503.

44. Nakashima K, Ito $Y$, Yamaguchi-Shinozaki K: Transcriptional regulatory networks in response to abiotic stresses in Arabidopsis and grasses. Plant Physiology 2009, 149:88-95.

45. Smit P, Raedts J, Portyanko V, Debelle F, Gough C, Bisseling T, Geurts R: NSP1 of the GRAS protein family is essential for rhizobial Nod factorinduced transcription. Science 2005, 308(5729):1789-1791.

46. Gallagher K, Benfey P: Both the conserved GRAS domain and nuclear localization are required for SHORT-ROOT movement. The Plant Journal 2009, 57(5):785-797.

47. Itoh H, Shimada A, Ueguchi-Tanaka M, Kamiya N, Hasegawa Y, Ashikari M, Matsuoka M: Overexpression of a GRAS protein lacking the DELLA domain confers altered gibberellin responses in rice. Plant Journal 2005, 44(4):669-679.

48. Guo H, Jiao Y, Di C, Yao D, Gaihua Z, Zheng X, Lan L, Qunlian Z, Guo A, Su Z: Discovery of Arabidopsis GRAS family genes in response to osmotic and drought stresses. Chinese Bulletin of Botany 2009, 44(3):290-299.
49. Yin Y, Wang Z, Mora-Garcia S, Li J, Yoshida S, Asami T, Chory J: BES1 accumulates in the nucleus in response to brassinosteroids to regulate gene expression and promote stem elongation. Cell 2002, 109(2):181-191.

50. Chao Q, Rothenberg M, Solano R, Roman G, Terzaghi W, Ecker J: Activation of the ethylene gas response pathway in Arabidopsis by the nuclear protein ETHYLENE-INSENSITIVE3 and related proteins. Cell 1997, 89(7):1133-1144.

51. Rooney M, Ferl R: Sequences of three Arabidopsis general regulatory factor genes encoding GF14 (14-3-3) proteins. Plant Physiology 1995, 107:283-284

52. Chen F, Li Q, Sun L, He Z: The rice 14-3-3 gene family and its involvement in responses to biotic and abiotic stress. DNA research 2006, 13(2):53-63.

53. Xu W, Shi W: Expression profiling of the 14-3-3 gene family in response to salt stress and potassium and iron deficiencies in young tomato (Solanum lycopersicum) roots: Analysis by real-time RTPCR. Annals of Botany 2006, 98(5):965-974.

54. Wei X, Zhang Z, Li Y, Wang X, Shao S, Chen L, Li X: Expression analysis of two novel cotton 14-3-3 genes in root development and in response to salt stress. Progress in Natural Science 2009, 19(2):173-178.

55. Fujii $\mathrm{H}$, Chiou T, Lin S, Aung K, Zhu J: A miRNA involved in phosphatestarvation response in Arabidopsis. Current Biology 2005, 15(22):2038-2043.

56. Sunkar R, Chinnusamy V, Zhu J, Zhu J: Small RNAs as big players in plant abiotic stress responses and nutrient deprivation. Trends in plant science 2007, 12(7):301-309.

57. Zhao B, Liang R, Ge L, Li W, Xiao H, Lin H, Ruan K, Jin Y: Identification of drought-induced microRNAs in rice. Biochemical and Biophysical Research Communications 2007, 354(2):585-590.

58. Liu H, Tian X, Li Y, Wu C, Zheng C: Microarray-based analysis of stressregulated microRNAs in Arabidopsis thaliana. RNA 2008, 14(5):836-843.

59. Zhou X, Wang G, Sutoh K, Zhu J, Zhang W: Identification of cold-inducible microRNAs in plants by transcriptome analysis. BBA-Gene Regulatory Mechanisms 2008, 1779(11):780-788.

60. Sunkar R, Zhou X, Zheng Y, Zhang W, Zhu J: Identification of novel and candidate miRNAs in rice by high throughput sequencing. BMC Plant Biology 2008, 8:25.

61. Ding D, Zhang L, Wang H, Liu Z, Zhang Z, Zheng Y: Differential expression of miRNAs in response to salt stress in maize roots. Annals of Botany 2009, 103:29-38.

62. Zhou X, Wang G, Zhang W: UV-B responsive microRNA genes in Arabidopsis thaliana. Molecular Systems Biology 2007, 3:103.

63. Lu S, Sun Y, Shi R, Clark C, Li L, Chiang V: Novel and mechanical stressresponsive microRNAs in Populus trichocarpa that are absent from Arabidopsis. The Plant Cell Online 2005, 17(8):2186-2203.

64. Phillips J, Dalmay T, Bartels D: The role of small RNAs in abiotic stress. FEBS letters 2007, 581(19):3592-3597.

65. Altschul S, Gish W, Miller W, Myers E, Lipman D: Basic local alignment search tool. J mol Biol 1990, 215(3):403-410.

66. miRBase. [http://microrna.sanger.ac.uk/sequences/].

67. Griffiths-Jones S, Saini HK, van Dongen S, Enright AJ: miRBase: tools for microRNA genomics. Nucleic Acids Research 2008, 36:D154-158.

68. Griffiths-Jones S, Grocock RJ, van Dongen S, Bateman A, Enright AJ: miRBase: microRNA sequences, targets and gene nomenclature. Nucleic Acids Research 2006, 34:D140-144.

69. Griffiths-Jones S: The microRNA Registry. Nucleic Acids Research 2004, 32: D109-111.

70. Sunkar R, Kapoor A, Zhu J: Posttranscriptional induction of two Cu/Zn superoxide dismutase genes in Arabidopsis is mediated by downregulation of miR398 and important for oxidative stress tolerance. The Plant Cell Online 2006, 18(8):2051-2065.

71. Wang Y, Li P, Cao X, Wang X, Zhang A, Li X: Identification and expression analysis of miRNAs from nitrogen-fixing soybean nodules. Biochemical and Biophysical Research Communications 2009, 378(4):799-803.

72. Miyashima S, Hashimoto T, Nakajima K: ARGONAUTE1 Acts in Arabidopsis root radial pattern formation independently of the SHR/SCR pathway. Plant Cell Physiol 2009, 50(3):626-634.

73. Affymetrix ${ }^{\oplus}$ GeneChip ${ }^{\oplus}$ Expression Analysis Technical Manual. [http:// www.affymetrix.com/support/downloads/manuals/expression analysis technical manual.pdf].

74. dChip Software. [http://biosun1.harvard.edu/complab/dchip/]. 
75. Li C, Wong WH: Model-based analysis of oligonucleotide arrays: Expression index computation and outlier detection. Proceedings of the National Academy of Sciences of the United States of America 2001, 98:31-36.

76. McClintick J, Edenberg H: Effects of filtering by Present call on analysis of microarray experiments. BMC Bioinformatics 2006, 7:49.

77. Huber W, von Heydebreck A, Sultmann H, Poustka A, Vingron M: Variance stabilization applied to microarray data calibration and to the quantification of differential expression. Bioinformatics 2002, 18(Suppl 1) S96-S104.

78. Storey JD, Tibshirani R: Statistical significance for genome wide studies. Proceedings of the National Academy of Sciences of the United States of America 2003, 100(16):9440-9445.

79. Benjamini $Y$, Hochberg $Y$ : Controlling the false discovery rate: a practical and powerful approach to multiple testing. Journal of the Royal Statistical Society. Series B (Methodological) 1995, 57:289-300.

80. EDGE. [http://www.genomine.org/edge/].

81. Leek JT, Monsen E, Dabney AR, Storey JD: EDGE: extraction and analysis of differential gene expression. Bioinformatics 2006, 22(4):507-508.

82. TM4: MeV. [http://www.tm4.org/mev.html].

83. Saeed A, Sharov V, White J, Li J, Liang W, Bhagabati N, Braisted J, Klapa M, Currier T, Thiagarajan M: TM4: a free, open-source system for microarray data management and analysis. Biotechniques 2003, 34(2):374-378.

84. Affymetrix ${ }^{\oplus}$ website. [http://affymetrix.com/index.affx].

85. Soybean GeneChip ${ }^{\otimes}$ and Arabidopsis ATH1 array annotation file. [http:// seedgenenetwork.net/annotate].

86. Agresti A: A survey of exact inference for contingency tables. Statistical Science 1992, 131-153.

87. Rozen S, Skaletsky H: Primer3 on the WWW for general users and for biologist programmers. Methods in Molecular Biology 2000, 132:365-386.

88. Pfaffl MW: A new mathematical model for relative quantification in realtime RT-PCR. Nucleic Acids Research 2001, 29:2002-2007.

89. Feng J, Liu D, Pan Y, Gong W, Ma L, Luo J, Deng X, Zhu Y: An annotation update via cDNA sequence analysis and comprehensive profiling of developmental, hormonal or environmental responsiveness of the Arabidopsis AP2/EREBP transcription factor gene family. Plant molecular biology 2005, 59(6):853-868.

doi:10.1186/1471-2229-10-153

Cite this article as: Ge et al: Global transcriptome profiling of wild soybean (Glycine soja) roots under $\mathrm{NaHCO}_{3}$ treatment. BMC Plant Biology 2010 10:153.

\section{Submit your next manuscript to BioMed Central and take full advantage of:}

- Convenient online submission

- Thorough peer review

- No space constraints or color figure charges

- Immediate publication on acceptance

- Inclusion in PubMed, CAS, Scopus and Google Scholar

- Research which is freely available for redistribution 